\title{
Effects of fatty acids on skeletal muscle cell differentiation in vitro
}

\author{
Matthew S. Hurley, Claire Flux, Andrew M. Salter and John M. Brameld* \\ Division of Nutritional Sciences, University of Nottingham, School of Biosciences, Sutton Bonington Campus, \\ Loughborough LE12 5RD, UK
}

(Received 29 April 2005 - Revised 23 September 2005 - Accepted 28 November 2005)

\begin{abstract}
Previous studies have shown stimulatory effects of linoleic acid (LA, C18:2) on differentiation of rat muscle cells in culture (Allen et al. 1985), but there appears to be little investigation of the effects of other fatty acids. The present study therefore compared the effects of different fatty acids on muscle cell differentiation in vitro. L6 myoblasts were cultured (Dulbecco's Modified Eagles Medium $+10 \%$ fetal calf serum) in six-well plates until $80 \%$ confluent (day 0). Cells were then either harvested or the medium switched to differentiation medium (Dulbecco's Modified Eagles Medium $+2 \%$ horse serum), supplemented with fatty acid or drug treatments. Cells were harvested on days $0-5$ and assayed for creatine kinase (CK), protein and DNA contents, to give a measure of differentiation (CK/DNA). Initial studies indicated a stimulatory effect of the cis9,trans $11(\mathrm{c} 9, \mathrm{t} 11)$ isomer of conjugated linoleic acid (CLA) relative to control. By contrast, the trans 10 , cis 12 (t10,c12) isomer of CLA inhibited differentiation. Further experiments indicated that inhibition of differentiation by the t10,c12 CLA isomer was dose-dependent (up to $200 \mu \mathrm{M}$ ) and may be via increased cell proliferation. LA and c9,t11 CLA stimulated differentiation at low concentrations (up to $50 \mu \mathrm{M}$ ), but inhibited differentiation at high concentrations $(200 \mu \mathrm{M})$. In contrast, oleic acid stimulated differentiation at all concentrations, whereas the saturated fatty acid, palmitic acid, had no effect. The mechanism appeared not to involve either peroxisome proliferator-activated receptors $\alpha$ or $\gamma$. The data suggest that only unsaturated fatty acids have an effect and the presence or absence of a cis-9 double bond may be important.
\end{abstract}

Fatty acids: PUFA: Conjugated linoleic acid: Skeletal muscle differentiation: Myogenesis

There is increasing evidence to suggest that fatty acids play a major role in regulating metabolism through effects on gene expression (Clarke, 2000). For example, fatty acids or their derivatives may be specific agonists of the peroxisome proliferator-activated receptor (PPAR). The nuclear hormone receptors play an important role in tissue differentiation. For example, PPAR $\gamma$ is essential in the differentiation of adipose tissue. Thus through regulating the activity of PPAR, or other transcription factors, fatty acids may play a key role in regulating tissue differentiation.

Previous in vitro studies have shown stimulatory effects of linoleic acid (LA) on differentiation of rat skeletal muscle satellite cells into myotubes (Allen et al. 1985). However, there appears to be little in the literature investigating the effects of other fatty acids. In recent years attention has focussed on conjugated linoleic acid (CLA). This group of positional and geometric isomers of conjugated dienoic derivatives of LA have been suggested to have a range of human health benefits including antiobesity and antidiabetic effects (Kelly, 2001; Pariza et al. 2001). CLA has been shown to decrease fat mass in rodents and pigs and increase insulin sensitivity in rodents (Pariza et al. 2001). Some of the in vivo studies indicate that the change in body composition, which often does not involve a change in body weight, is associated not only with a decrease in fat mass but also an increase in lean mass (Pariza et al. 2001). CLA have also been reported to be potent PPAR agonists (Belury, 2002).

The present study therefore compared the effects of different fatty acids, including LA and individual and mixed isomers of CLA, on muscle cell differentiation, as measured by creatine kinase (CK) content (IU/mg DNA), which is now considered the best method of quantifying differentiation (Clemente et al. 2005). Obviously, effects on cell differentiation can be brought about by changes in cell proliferation or cell death, such that an inhibition of differentiation might be due to either an induction of cell proliferation or toxic effects resulting in cell death. To investigate these two possibilities, we investigated the effects of the different fatty acids on the DNA content (mg/well). The effects were then compared with those of known specific PPAR $\alpha$ and PPAR $\gamma$ agonists in order to investigate whether these transcription factors represented a possible mode of action for the observed fatty acid effects.

\section{Materials and methods}

Muscle cell cultures

L6 myoblasts are a myoblast cell line originally derived from rat skeletal muscle and were kindly donated by Dr Cliff Bailey 
of Aston University. The L6 myoblasts were cultured in growth medium consisting of Dulbecco's Modified Eagles Medium (Sigma Chemical Co., Poole, UK) supplemented with $10 \%$ fetal calf serum (Sigma), 100 units $/ \mathrm{ml}$ penicillin and $0.1 \mathrm{mg} /$ $\mathrm{ml}$ streptomycin (Sigma) in six-well plates (Corning) until they were approximately $80 \%$ confluent. At this time-point (day 0), cells were either harvested for analysis or the medium was changed to differentiation medium (Dulbecco's Modified Eagles Medium containing 2\% horse serum; Sigma), supplemented with the various fatty acid or drug treatments. All fatty acids were supplied bound to bovine serum albumin (BSA; Sigma). Fatty acid-albumin complexes were prepared by a modification of the method of Van Harken et al. (1969) as described by Goldstein et al. (1983). The molar ratio of fatty acid to BSA was 6.7. In order to attempt to identify a possible mechanism for the observed effects of fatty acids on muscle differentiation, the PPAR agonists Rosiglitazone (donated by GlaxoSmithKline) and Wy14643 (donated by Dr D. Bell, University of Nottingham) were tested and were initially dissolved in dimethyl sulphoxide, which was therefore used as a control in these studies.

At various time-points (days 0,1, 2, 3, 4 and/or 5), cells from each well (one well per treatment per time-point per experiment) were washed with PBS before being scraped into $1 \mathrm{ml} 50 \mathrm{~mm}$-sodium citrate buffer $(\mathrm{pH}$ 6.75) and stored frozen $\left(-40^{\circ} \mathrm{C}\right)$ prior to assay for $\mathrm{CK}$, protein and DNA contents. The time-points varied depending upon whether a treatment was thought to stimulate or inhibit differentiation. For treatments that stimulated differentiation, earlier time-points were used since prolonged culture of differentiated myotubes leads to eventual loss of those myotubes due to them contracting and lifting off the culture plate, which can result in an initial increase then a decrease in measurements of $\mathrm{CK}$ activity/content.

\section{Analyses of creatine kinase, DNA and protein contents}

The cells in citrate buffer were lysed after thawing by sonication, and the CK content measured using a CK assay kit (Sigma). The volumes were modified for use on a ninety-six-well absorbance platereader, and the values of $\mathrm{CK}$ activity (IU/ml) were measured relative to a CK control (Sigma). The DNA content $(\mathrm{mg} / \mathrm{ml})$ was measured via a ninety-six-well fluorescence platereader assay (Rago et al. $1990)$ and protein content $(\mathrm{mg} / \mathrm{ml})$ was measured using the Lowry method (Lowry et al. 1951), with the volumes again modified for use on a ninety-six-well absorbance platereader.

\section{Statistical analyses}

Each experiment was repeated three or four times to allow statistical analysis. CK specific activities (IU/mg DNA), protein content (mg/mg DNA) and DNA content (mg/well) were analysed for effects of fatty acid and time by two-way ANOVA using SPSS statistical package version 13.0.1 (SPSS Inc., Chicago, IL, USA). Differences of $P<0.05$ were considered significant. The DNA-adjusted CK specific activity (IU/mg DNA) was used as the quantitative measure of differentiation and DNA content (mg/well) was used to investigate possible effects on cell proliferation or death.

\section{Results}

Preliminary studies compared the effects of LA (C18:2), oleic acid (OA, C18:1), CLA mix (90\% CLA consisting of approximately 50:50 cis 9 ,trans 11 (c9,t11) CLA and trans 10, cis 12 (t10,c12) CLA), pure c9,t11 CLA, pure t10,c12 CLA (all at $50 \mu \mathrm{M})$ and control (BSA). These studies indicated a significant interaction between fatty acid and time $(P=0 \cdot 002$; Table 1), such that at the day 3 time-point, the t10,c12 isomer of CLA inhibited differentiation (CK content), but the c9,t11 CLA isomer stimulated differentiation relative to the BSA control. These quantitative changes in the marker for differentiation (CK IU/mg DNA) were matched by visual changes in the cultured cells (appearance of more or fewer myotubes) observed down the microscope (Fig. 1), with similar changes in the protein content (mg protein/mg DNA) also being observed (data not shown).

To investigate these effects further, dose response studies were carried out for each individual fatty acid/CLA isomer,

Table 1. Effects of different fatty acids on DNA content and differentiation (measured as creatine kinase (CK) content) of L6 myoblasts in culture* (Mean values and standard deviations, $n$ 4, except time-point 3 where $n 3$ )

\begin{tabular}{|c|c|c|c|c|c|c|c|c|c|c|c|c|}
\hline \multirow[b]{3}{*}{ Fatty acid $(50 \mu \mathrm{M})$} & \multicolumn{6}{|c|}{ DNA content (mg/well) } & \multicolumn{6}{|c|}{ CK content (IU/mg DNA) } \\
\hline & \multicolumn{6}{|c|}{ Time of differentiation (d) } & \multicolumn{6}{|c|}{ Time of differentiation (d) } \\
\hline & Mean & SD & Mean & SD & Mean & SD & Mean & SD & Mean & SD & Mean & SD \\
\hline Control (BSA) & 0.0255 & 0.0084 & 0.0543 & 0.0285 & 0.0548 & 0.0152 & 0.536 & 0.235 & $2 \cdot 278$ & 0.440 & $3 \cdot 312$ & 0.987 \\
\hline CLA mix & 0.0315 & 0.0124 & 0.0350 & 0.0176 & 0.0465 & 0.0322 & 0.433 & 0.178 & 1.574 & 0.325 & 1.416 & 0.195 \\
\hline Linoleic acid & 0.0295 & 0.0099 & 0.0797 & 0.0482 & 0.0945 & 0.0234 & 0.568 & 0.081 & $1 \cdot 363$ & 0.269 & 2.904 & 1.697 \\
\hline Oleic acid & 0.0340 & 0.0170 & 0.0630 & 0.0210 & 0.0790 & 0.0243 & 0.522 & 0.123 & 2.605 & 0.726 & 2.923 & 0.646 \\
\hline $\mathrm{t} 10, \mathrm{c} 12 \mathrm{CLA}$ isomer & 0.0313 & 0.0109 & 0.0393 & 0.0049 & 0.0385 & 0.0101 & 0.509 & 0.189 & 0.981 & 0.239 & $1 \cdot 300$ & 0.426 \\
\hline
\end{tabular}

BSA, bovine serum albumin; c9,t11 isomer, cis9,trans11 isomer; CLA, conjugated linoleic acid; t10,c12 isomer, trans10,cis12 isomer.

${ }^{*}$ For details of procedures, see this page. There were significant fatty acid $\times$ time interactions for both DNA (mg/well) and CK (IU/mg DNA) content ( $P=0.002$ for both). As expected, differentiation (CK content) increased with time in the control samples, with an increase in DNA also being observed. The t10,c12 CLA isomer appeared to inhibit differentiation while the $\mathrm{c} 9, \mathrm{t} 11 \mathrm{CLA}$ isomer appeared to stimulate differentiation, particularly at the day 3 time-point. 

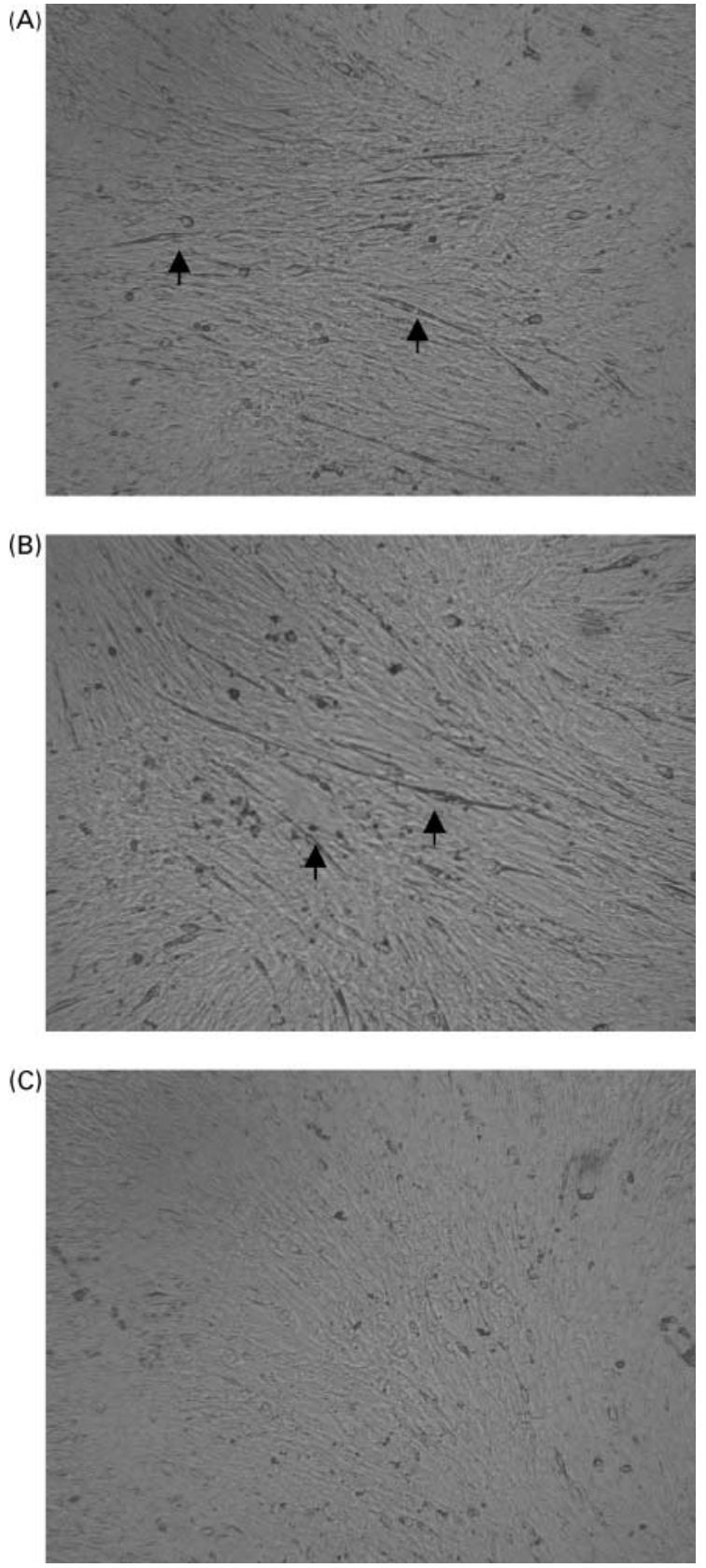

Fig. 1. Effects of conjugated linoleic acid (CLA) isomers or control (bovine serum albumin) on differentiation of L6 myoblasts in culture. Photographs ( $\times 40$ magnification) are representative of cultures treated for $3 \mathrm{~d}$. Small arrows indicate presence of myotubes. (A), Control; (B), cis9, trans11 CLA $(50 \mu \mathrm{M}) ;(\mathrm{C})$, trans 10, cis12 CLA $(50 \mu \mathrm{M})$.

using doses of $0,12 \cdot 5,25,50,100$ and $200 \mu \mathrm{M}$. Palmitic acid (C16:0) was also studied as an example of a saturated fatty acid. Treatment with the $110, c 12$ CLA isomer (C18:2) resulted in a dose-dependent increase in DNA content and an inhibition of differentiation (Table 2), with very little differentiation being observed with doses of 100 and $200 \mu \mathrm{M}$ on days 3 and $4(P=0.006$ for both, concentration $\times$ time interaction $)$.

In comparison, treatment with the $\mathrm{c} 9, \mathrm{t} 11$ isomer of CLA (C18:2) stimulated differentiation at lower doses (12.5, 25 and $50 \mu \mathrm{M}$; Table 3), but inhibited differentiation at the

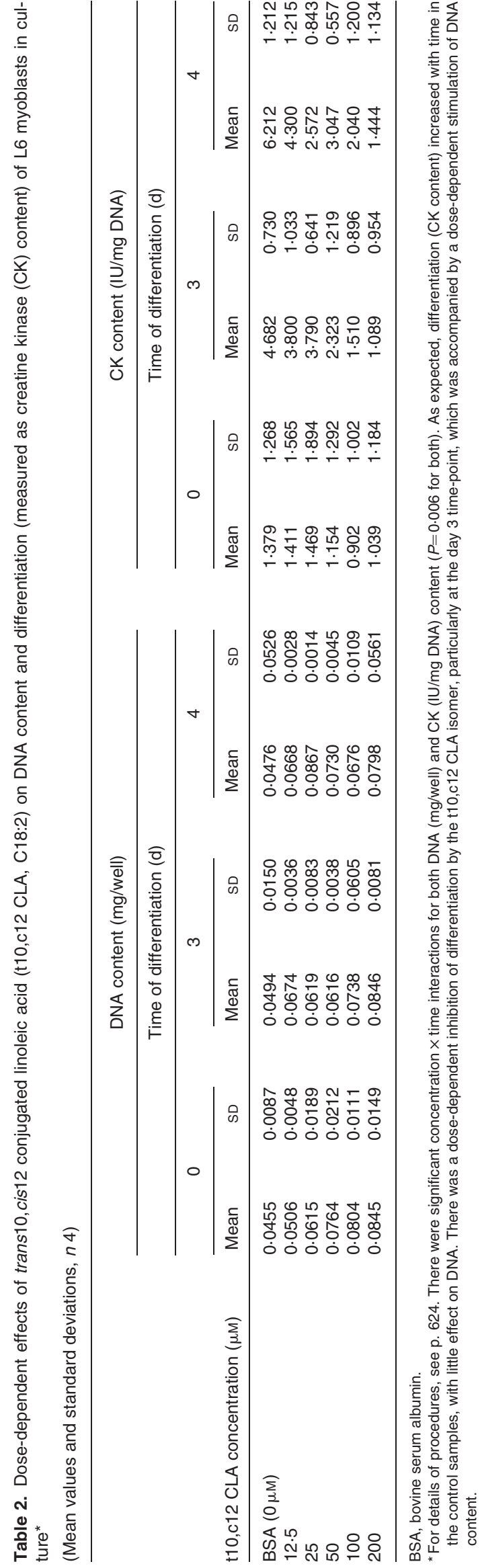


highest dose $(200 \mu \mathrm{M} ; P<0 \cdot 001$, concentration $\times$ time interaction), with no effect on DNA content other than an increase with time $(P<0 \cdot 001$, time effect).

Similarly, LA (C18:2 c9,c12) stimulated differentiation at the lowest dose $(12.5 \mu \mathrm{M}$; Table 4$)$ and inhibited differentiation at the highest dose $(200 \mu \mathrm{M} ; P<0.001$, concentration $\times$ time interaction), with no effect on DNA content other than an increase with time $(P<0.001$ for time effect). Note that, as in the preliminary study (Table 1 ), $50 \mu \mathrm{M}$-LA appeared to have no effect on differentiation.

OA (C18:1 c9) was the only MUFA studied and it was found to stimulate differentiation at all concentrations (Table 5), with no obvious dose-dependency $(P<0.002$, concentration $\times$ time interaction). This was different from the preliminary study (Table 1) where no significant effect of $50 \mu \mathrm{M}-\mathrm{OA}$ on differentiation was observed, although there was a numerical increase in CK content on day 3. In general, there was little obvious effect of OA on DNA content, which increased with time, except that the highest doses $(100$ and $200 \mu \mathrm{M})$ reduced the DNA content $(P<0.002$, concentration $\times$ time interaction) at the last time-point (day 4$)$.

Palmitic acid (C16:0), the only saturated fatty acid studied, had no effect on differentiation (Table 6), with only the expected time effect being observed $(P<0.001$ for time effect). DNA content increased with time in control samples, with no effect of palmitic acid at low doses, but a decrease in DNA content at the highest dose $(P<0.001$, concentration $\times$ time interaction), particularly at the day 3 and 4 time-points (Table 6). This may be suggestive of a toxic effect of high doses of this particular fatty acid.

As in the preliminary study, these quantitative changes in the marker for differentiation (CK IU/mg DNA) were matched by visual changes in the cultured cells (appearance of more or fewer myotubes) observed down the microscope (data not shown), with similar trends also observed for changes in protein content (data not shown).

To further characterise the mechanism for the observed effects of the different fatty acids, two PPAR agonists were tested. Rosiglitazone, a PPAR $\gamma$ agonist, was found to have no significant effects on differentiation or DNA content, with the only effects being the expected increase in differentiation and DNA content with time (Table 7; $P<0.001$ for effect of time on both). The PPAR $\alpha$ agonist, Wy14643, appeared to have a small, but significant inhibitory effect on differentiation $(P<0.001$, concentration $\times$ time interaction $)$, possibly due to increased DNA content $(P=0.002$, concentration $\times$ time interaction), but there was no obvious dose-dependency (Table 8) and the magnitude of the effect was very small compared to that of t10,c12 CLA (Table 2).

\section{Discussion}

To our knowledge, this is the first study to compare the effects of different fatty acids on the differentiation of skeletal muscle cells. Interestingly, the two main isomers of CLA (c9,t11 and t10,c12) showed opposite effects, with c9,t11 CLA stimulating early differentiation and t10,c12 CLA inhibiting differentiation. LA (C18:2 c9c12) and OA (C18:1 c9) had similar stimulatory effects to c9,t11 CLA; while the only saturated fatty acid tested, palmitic acid (C16:0), had no effect. The stimulatory effect of LA confirms previous work in rat satellite 
Fatty acids and muscle differentiation
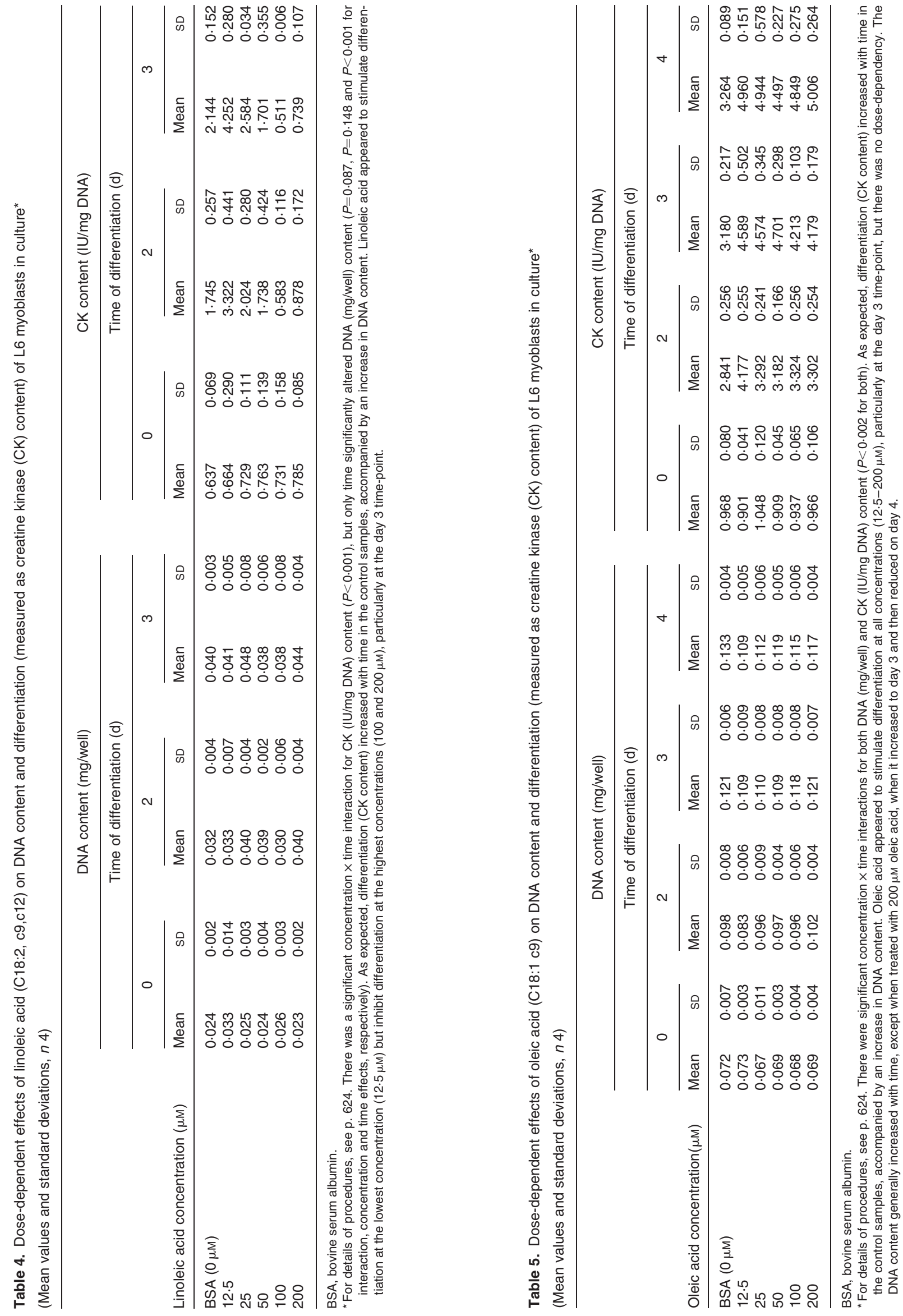


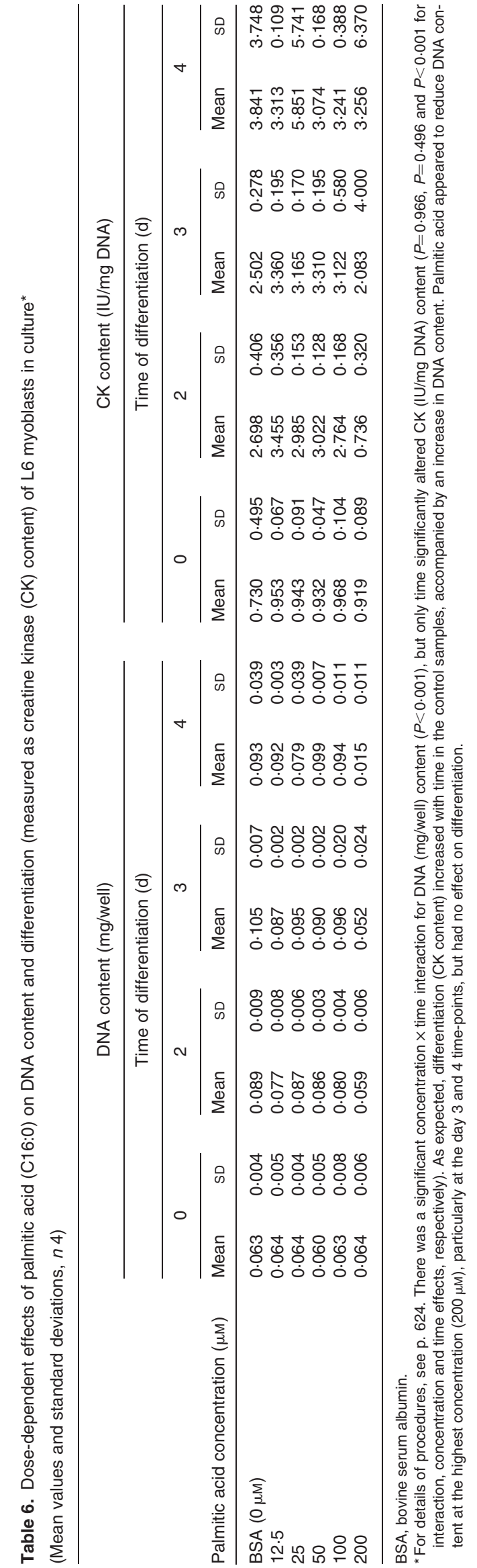

cells (Allen et al. 1985). The pro-differentiation effects of OA, LA and particularly c9,t11 CLA may relate to these fatty acids having anti-cancer effects (see Kelly, 2001; Pariza et al. 2001), since cells must stop proliferating in order to differentiate, although there is no evidence for this from the DNA content data. Indeed, the pro-differentiation effects of the low concentrations of fatty acids $(12.5-50 \mu \mathrm{M})$ were not associated with any effects on DNA content, indicating that they were not via effects on cell proliferation or death. In contrast, the anti-differentiation effects of t10,c12 CLA may relate to increased proliferation, since DNA content was increased. Indications that there may be toxic effects of the fatty acids were only seen in the case of palmitic acid, where high concentrations $(100$ or $200 \mu \mathrm{M})$ appeared to decrease DNA content. Of the fatty acids studied, the presence of at least one double bond appears to be important in stimulating differentiation. Why the t10,c12 CLA isomer should have apparently opposite effects to the other unsaturated fatty acids is not obvious, but it is possible that this relates to the position of the double bonds. All of the other unsaturated fatty acids tested contain a double bond in the cis 9 position. Alternatively it may relate to the antioxidant/pro-oxidant activity of the fatty acids, since t10,c12 CLA has been shown to be more potent as an antioxidant than other unsaturated fatty acids (Leung \& Liu, 2000).

In adipose tissue it is well established that PPAR $\gamma$ plays an important role in cellular differentiation (see Brun et al. 1996) and that fatty acids are able to regulate adipocyte differentiation (adipogenesis), possibly by acting as PPAR $\gamma$ agonists or antagonists. Interestingly, OA (C18:1) has been shown to stimulate differentiation of porcine adipocytes (Ding \& Mersmann, 2001), while palmitic acid (C16:0) and other saturated fatty acids had no effect. A mix of CLA isomers has also been shown to inhibit differentiation of 3T3-L1 adipocytes (Brodie et al. 1999), and this appears to relate specifically to the t10,c12 isomer (Brown et al. 2001; Lin et al. 2001). These effects are similar to those described here in muscle cells. Skeletal muscle is known to express all three isoforms of PPAR $(\alpha, \beta / \delta$ and $\gamma$; Holst et al. 2003; Wolf, 2004; Grimaldi, 2005), with all appearing to regulate lipid metabolism, particularly fatty acid uptake and catabolism. Since unsaturated fatty acids may act as agonists of PPAR, we investigated whether known PPAR agonists could mimic the observed effects of fatty acids. The apparent lack of, or at most small, effect of the two PPAR agonists (Wy 14643 and Rosiglitazone) suggests that the observed effects of fatty acids on muscle cell differentiation do not involve PPAR $\alpha$ or $\gamma$. However, we cannot rule out an effect via PPAR $\beta / \delta$. Possible alternative mechanisms include (1) modulation of the activity of other transcription factors; and (2) oxidant/antioxidant properties of the fatty acids. A recent publication (Orzechowski et al. 2002) demonstrated stimulatory effects of micromolar concentrations of hydrogen peroxide on L6 myoblast differentiation; whereas millimolar concentrations led to cell death by apoptosis. The effects of hydrogen peroxide are very similar to our observed effects of LA and c9,t11 CLA on differentiation, suggesting that similar oxidant/antioxidant effects may be involved. Indeed, we have recently shown similar dose-dependent effects of hydrogen peroxide in our L6 cultures (unpublished results). One of the downstream targets of hydrogen peroxide is the transcription factor, nuclear 
Table 7. Dose-dependent effects of the peroxisome proliferator-activated receptor $\gamma$ agonist, Rosiglitazone, on DNA content and differentiation (measured as creatine kinase (CK) content) of L6 myoblasts in culture*

(Mean values and standard deviations, $n 4$ )

\begin{tabular}{|c|c|c|c|c|c|c|c|c|c|c|c|c|}
\hline \multirow[b]{4}{*}{ Rosiglitazone concentration $(\mu \mathrm{M})$} & \multicolumn{6}{|c|}{ DNA content (mg/well) } & \multicolumn{6}{|c|}{ CK content (IU/mg DNA) } \\
\hline & \multicolumn{6}{|c|}{ Time of differentiation (d) } & \multicolumn{6}{|c|}{ Time of differentiation (d) } \\
\hline & \multicolumn{2}{|c|}{0} & \multicolumn{2}{|c|}{1} & \multicolumn{2}{|c|}{4} & \multicolumn{2}{|c|}{0} & \multicolumn{2}{|c|}{1} & \multicolumn{2}{|c|}{4} \\
\hline & Mean & SD & Mean & SD & Mean & SD & Mean & SD & Mean & SD & Mean & SD \\
\hline Control & 0.0338 & 0.0064 & 0.0328 & 0.0109 & 0.0465 & 0.0057 & 0.710 & 0.126 & 1.875 & 0.733 & $3 \cdot 843$ & 1.157 \\
\hline 0.1 & 0.0340 & 0.0041 & 0.0368 & 0.0096 & 0.0495 & 0.0025 & 0.671 & 0.199 & 1.445 & 0.461 & 4.403 & 0.887 \\
\hline 1 & 0.0343 & 0.0039 & 0.0370 & 0.0016 & 0.0460 & 0.0056 & 0.726 & 0.164 & $1 \cdot 248$ & 0.466 & 4.410 & $1 \cdot 128$ \\
\hline 10 & 0.0338 & 0.0074 & 0.0383 & 0.0078 & 0.0478 & 0.0072 & 0.756 & 0.249 & $1 \cdot 232$ & 0.466 & 4.557 & 1.518 \\
\hline
\end{tabular}

DMSO, dimethyl sulphoxide.

${ }^{*}$ For details of procedures, see p. 624. Note that there are two controls, an untreated and a DMSO-treated, since DMSO was used as the vehicle for the Rosiglitazone. There were no significant concentration $\times$ time interactions for either CK (IU/mg DNA) or DNA (mg/well) content $(P=0.475$ and $P=0.667$, respectively). Only time significantly altered CK (IU/mg DNA) or DNA (mg/well) content $(P<0.001$ for both). Hence, differentiation (CK content) increased with time in the control and treated samples, with no effect of DMSO or Rosiglitazone $(P=0.969)$. Similarly, DNA content increased with time, but there was no effect of DMSO or Rosiglitazone $(P=0.690)$.

Table 8. Dose-dependent effects of the peroxisome proliferator-activated receptor $\alpha$ agonist, Wy14643, on DNA content and differentiation (measured as creatine kinase (CK) content) of L6 myoblasts in culture*

(Mean values and standard deviations, $n$ 4)

\begin{tabular}{|c|c|c|c|c|c|c|c|c|c|c|c|c|}
\hline \multirow[b]{3}{*}{ Wy14643 concentration $(\mu \mathrm{M})$} & \multicolumn{6}{|c|}{ DNA content (mg/well) } & \multicolumn{6}{|c|}{ CK content (IU/mg DNA) } \\
\hline & \multicolumn{6}{|c|}{ Time of differentiation (d) } & \multicolumn{6}{|c|}{ Time of differentiation (d) } \\
\hline & Mean & SD & Mean & SD & Mean & SD & Mean & SD & Mean & SD & Mean & SD \\
\hline Control & 0.0606 & 0.0063 & 0.0645 & 0.0069 & 0.0745 & 0.0063 & 0.786 & 0.110 & 3.463 & 0.128 & 3.529 & 0.083 \\
\hline 5 & 0.0600 & 0.0100 & 0.0799 & 0.0107 & 0.0859 & 0.0103 & 0.744 & 0.130 & $2 \cdot 814$ & 0.259 & 3.208 & 0.252 \\
\hline 10 & 0.0588 & 0.0063 & 0.0811 & 0.0069 & 0.0853 & 0.0075 & 0.836 & 0.085 & 2.579 & 0.394 & 3.238 & 0.252 \\
\hline 50 & 0.0536 & 0.0094 & 0.0700 & 0.0062 & 0.0772 & 0.0054 & 0.909 & 0.229 & 2.548 & 0.204 & $3 \cdot 182$ & 0.252 \\
\hline 100 & 0.0608 & 0.0048 & 0.0643 & 0.0063 & 0.0664 & 0.0080 & 0.857 & 0.053 & 2.077 & 0.063 & 3.105 & 0.096 \\
\hline
\end{tabular}

DMSO, dimethyl sulphoxide.

* For details of procedures, see p. 624. Note that there are two controls, an untreated and a DMSO-treated, since DMSO was used as the vehicle for the Wy14643. There were significant concentration $\times$ time interactions for both DNA (mg/well) and CK (IU/mg DNA) content $(P=0.002$ and $P<0.001$, respectively). As expected, differentiation (CK content) increased with time in the control (untreated) samples, accompanied by an increase in DNA content. Wy14643 appeared to inhibit differentiation slightly in a dose-dependent manner, particularly at the day 2 time-point, and increased DNA content at low concentrations $(5-10 \mu \mathrm{M})$, with no effect at high concentrations. The magnitude of these effects were not as pronounced as for similar concentrations of the trans10,cis12 isomer of CLA.

factor kappa B, which responds directly to oxidative stress (Siebenlist et al. 1994). There is also evidence that insulinlike growth factor-I (IGF-I) activates nuclear factor kappa B in myeloma cells (Mitsiades et al. 2002), presumably via the IGF type-1 receptor. IGF-I and IGF-II were the first (and until recently only) factors known to stimulate muscle differentiation (see Brameld et al. 1998), with the effects of both being via the IGF type-1 receptor. Indeed, local expression of IGF-II may be an important autocrine regulator of muscle cell differentiation (see Brameld et al. 1998; Florini et al. 1991). Hence fatty acids, oxidative stress and IGF may all regulate muscle differentiation via common signalling mechanisms involving the activation of nuclear factor kappa B. Alternatively, fatty acids might regulate IGF-I or IGF-II production in muscle.

At the present time it is unclear how these effects in cell culture might translate into in vivo effects of different dietary fatty acids. As already mentioned, CLA has been reported to increase muscle mass, at least in some studies (see Kelly, 2001; Pariza et al. 2001). Most of the available evidence suggests that this effect is associated with the t10,c12 CLA isomer. The fact that $10, c 12$ CLA inhibits muscle cell differentiation, possibly by stimulating proliferation, may account for these in vivo observations and clearly requires further investigation. However, the present study does indicate that unsaturated fatty acids have the potential to regulate muscle gene expression and differentiation in a similar way to that already described in other tissues such as adipose tissue (Ding \& Mersmann, 2001).

\section{Acknowledgements}

The authors wish to thank Dr Cliff Bailey (Aston University) for kindly donating the L6 myoblast cell line, Dr David Bell (University of Nottingham) for kindly donating the 
Wy14643 and GlaxoSmithKline for kindly donating the Rosiglitazone. The work was funded by a University of Nottingham New Lecturers grant to J. M. B.

\section{References}

Allen RE, Luiten LS \& Dodson MV (1985) Effect of insulin and linoleic acid on satellite cell differentiation. J Anim Sci 60, 1571-1579.

Belury MA (2002) Dietary conjugated linoleic acid in health: physiological effects and mechanisms of action. Аппи Rev Nutr 22, 505-531.

Brameld JM, Buttery PJ, Dawson JM \& Harper JMM (1998) Nutritional and hormonal control of skeletal-muscle cell growth and differentiation. Proc Nutr Soc 57, 207-217.

Brodie AE, Manning VA, Ferguson KR, Jewell DE \& Hu CY (1999) Conjugated linoleic acid inhibits differentiation of pre- and postconfluent 3T3-L1 preadipocytes but inhibits cell proliferation only in preconfluent cells. J Nutr 129, 602-606.

Brown JM, Halvorsen YD, Lea-Currie YR, Geigerman C \& McIntosh M (2001) Trans-10, cis-12, but not cis-9, trans-11, conjugated linoleic acid attenuates lipogenesis in primary cultures of stromal vascular cells from human adipose tissue. J Nutr 131, 2316-2321.

Brun RP, Kim JB, Hu E, Altiok S \& Spiegelman BM (1996) Adipocyte differentiation: a transcriptional regulatory cascade. Curr Opin Cell Biol 8, 826-832.

Clarke SD (2000) Polyunsaturated fatty acid regulation of gene transcription: a mechanism to improve energy balance and insulin resistance. Br J Nutr 83, Suppl. 1, S59-S66.

Clemente CFMZ, Corat MAF, Saad STO \& Klebere G (2005) Differentiation of $\mathrm{C} 2 \mathrm{C} 12$ myoblasts is critically regulated by FAK signalling. Am J Physiol 289, R862-R870.

Ding S-T \& Mersmann HJ (2001) Fatty acids modulate porcine adipocyte differentiation and transcripts for transcription factors and adipocyte-characteristic proteins. J Nutr Biochem 12, 101-108.

Florini JR, Magri KA, Ewton DZ, James PL, Grindstaff K \& Rotwein PS (1991) 'Spontaneous' differentiation of skeletal myoblasts is dependent upon autocrine secretion of insulin-like growth factorII. J Biol Chem 266, 15917-15923.

Goldstein JL, Basu SK \& Brown MS (1983) Receptor-mediated endocytosis of low-density lipoprotein in cultured cells. Methods Enzymol 98, 241-260.
Grimaldi PA (2005) Regulatory role of peroxisome proliferator-activated receptor delta (PPAR $\delta$ ) in muscle metabolism. A new target for metabolic syndrome treatment? Biochimie 87, 5-8.

Holst D, Luquet S, Nogueira V, Kristiansen K, Leverve X \& Grimaldi PA (2003) Nutritional regulation and role of peroxisome proliferator-activated receptor $\delta$ in fatty acid catabolism in skeletal muscle. Biochim Biophys Acta 1633, 43-50.

Kelly GS (2001) Conjugated linoleic acid: a review. Altern Med Rev 6, 367-382.

Leung YH \& Liu RH (2000) trans-10, cis-12-Conjugated linoleic acid isomer exhibits stronger oxyradical scavenging capacity than cis-9, trans-11-conjugated linoleic acid isomer. J Agric Food Chem 48, $5469-5475$.

Lin Y, Kreeft A, Schuurbiers JAE \& Draijer R (2001) Different effects of conjugated linoleic acid isomers on lipoprotein lipase activity in 3T3-L1 adipocytes. J Nutr Biochem 12, 183-189.

Lowry OH, Rosebrough NJ, Farr AL \& Randall RJ (1951) Protein measurement with the Folin phenol reagent. J Biol Chem 193, 265-275.

Mitsiades CS, Mitsiades N, Poulaki V, et al. (2002) Activation of NFkappaB and upregulation of intracellular anti-apoptotic proteins via the IGF-1/Akt signaling in human multiple myeloma cells: therapeutic implications. Oncogene 21, 5673-5683.

Orzechowski A, Grizard J, Jank M, Gajkowska B, Lokociejewska M, Zaron-Teperek M \& Godlewski M (2002) Dexamethasonemediated regulation of death and differentiation of muscle cells. Is hydrogen peroxide involved in the process? Reprod Nutr Dev 42, 197-216.

Pariza MW, Park Y \& Cook ME (2001) The biologically active isomers of conjugated linoleic acid. Prog Lipid Res 40, $283-298$.

Rago R, Mitchen J \& Wilding G (1990) DNA fluorometric assay in 96-well tissue-culture plates using Hoechst-33258 after cell-lysis by freezing in distilled water. Anal Biochem 191, 31-34.

Siebenlist U, Franzoso G \& Brown K (1994) Structure, regulation and function of NF-kappaB. Annu Rev Cell Biol 10, 405-455.

Van Harken DR, Dixon CW \& Heimberg M (1969) Hepatic lipid metabolism in experimental diabetes $\mathrm{V}$. The effect of concentration of oleate on metabolism of triglycerides and on ketogenesis. $J$ Biol Chem 244, 2278-2285.

Wolf G (2004) Tissue-specific knockout defines peroxisome proliferator-activated receptor gamma function in muscle and liver. Nutr Rev 62, 253-255. 